International Journal of Child, Youth and Family Studies (2011) 3 \& 4: 473-493

\title{
MYTHOLOGIZING ASPERGER SYNDROME: EXPLORING IMPACTS ON SOCIAL JUSTICE FOR CHILDREN IN OUT-OF-HOME CARE
}

\author{
Irene Stevens
}

\begin{abstract}
While the majority of children affected by autistic spectrum disorders (ASD) remain at home and within their communities, a minority are so badly affected that they require out-of-home care. This article draws on some of the findings of the author's doctoral thesis. Social justice discourse and critical disability studies have alerted researchers to the foregrounding of privileged ideas in society. For this study, texts were analyzed using ideas from Foucault and Critical Discourse Analysis. Textual analysis revealed that the discourse of Asperger Syndrome comprises an association with high intelligence, special talents (especially in maths or computing) and possibly with genius. There is also a prevailing belief within the discourse of Asperger Syndrome that it is a "mild disorder". The voices of children who are seriously affected by Asperger Syndrome, to the extent that they may need out-of-home care, are absent. A field study that examined the views of potential and newly recruited child care practitioners demonstrated the ways in that incomplete messages from the discourse of Asperger Syndrome can affect practice.
\end{abstract}

Keywords: autism, Asperger Syndrome, disability, discourse analysis

Dr. Irene Stevens is a lecturer at and the research manager for the Scottish Institute for Residential Child Care, which is part of Strathclyde University in Glasgow, Scotland. She was previously a residential child care practitioner and her main research interests are out-of-home care, disability, and children's rights.

Correspondence on this article should be addressed to Dr. Irene Stevens, Scottish Institute of Residential Child Care, University of Strathclyde, Sir Henry Wood Building, 5th floor, Southbrae Drive, Jordanhill, Glasgow, G13 1PP. Contact: Irene.c.stevens@strath.ac.uk (+44-141 950 3683) 
Asperger Syndrome is named after Hans Asperger, the Austrian paediatrician who discovered the condition in 1944. Asperger noted that such children exhibited a range of behavioural difficulties, some of which could be severe. A few examples of these difficulties included a child described as "aggressive and lashed out with anything he could get hold of (including a hammer)" or "hit or verbally abused other children indiscriminately" (as cited in Frith, 1991, pp. 42 and 59). He also stated that they developed early language skills and that "the cleverest among them can overcome their difficulties by dint of sheer intellect" (as cited in Frith, 1991, p. 63). He referred to the affected children as "little professors" and maintained that they had high intelligence and were capable of abstract and original thought. The paper ends on a positive note in terms of outcomes, although Asperger did say that "the positive aspects of autism do not outweigh the negative ones” (as cited in Frith, 1991, p. 74).

The term Asperger Syndrome was first used by Wing (1981), referencing Asperger's work. She noted the 34 children in her study did not indulge in imaginative play and also that they lacked interest in relationships. She disagreed with two of Asperger's points. The first was that her children did not demonstrate early language skills. The second was that they did not demonstrate abstract original thought and high intelligence. Any special abilities they had could be explained by rote learning but not by a deep understanding of the subject. She questioned the hopeful view of the prognosis that was given by Asperger. Her group of children had a range of problems, related mostly to their lack of social awareness and need for sameness, to such an extent that in one of the cases, the young person had attempted suicide. Of the children she studied, she said that "the majority need help and guidance in sheltered settings for all of their lives" (Wing, 1991, p. 118). She acknowledged that some "manage to become reasonably wellfunctioning and even, in a few cases, markedly successful” (Wing, 1991, p. 118). In her view, however, this was not the norm.

Wing felt that the best way to describe the relationship between autism and Asperger Syndrome was to conceptualize them as part of a range of disorders that occupy a continuum (Wing, 1988). A place on the continuum could be decided on how seriously a person is affected by a "triad of impairments" in communication, relationships, and imagination. Professionals in the autism field have now adopted the notion of an autistic continuum or Autistic Spectrum Disorders (ASD). However, one of the weaknesses of the concept of a continuum is that Asperger Syndrome is considered to be a milder form of autism. This is refuted by researchers such as Gillberg (1991) who states that Asperger Syndrome “... cannot be dismissed at the drop of a hat as 'mild autism' and thereby relegated to the status of eccentricities in a textbook on child psychiatry” (as cited in Frith, 1991, p. 122). In other words, there is also a continuum of effects within Asperger Syndrome, ranging from mild to severe.

Links between genius and Asperger Syndrome have been suggested by Fitzgerald (2003, 2005). Using retrospective diagnosis of gifted individuals in history, he suggests that there is a genetic link between Asperger Syndrome and genius. The people he has diagnosed retrospectively include Wittgenstein, Michelangelo, and Mozart (among others). While Fitzgerald may well be correct in suggesting a genetic component, and while it may also be the case that some of these historical figures did have Asperger Syndrome, his methodology is 
highly flawed. He begins with the criteria for Asperger Syndrome and works from contemporary notes to fit the subject into the diagnosis. While some people with Asperger Syndrome have a special interest and a degree of focus that, when coupled with above-average intelligence and a high degree of support, can allow that person to excel in their field (e.g., Grandin, 1995; Willey, 1999), this is not the case for all those affected.

An examination of some of the research into academic achievement may give a clearer indication of how children and young people with Asperger Syndrome manage their lives. Reitzal and Szatmari (2003) reported on a long-term study examining academic achievement. The vast majority of children had long-term difficulties in school and their work was consistently below that of their peers. Interestingly, they also reported that there are few studies on neurocognitive profiles of children with Asperger Syndrome, and the specific focus on academic achievement is even sparser (as cited in Prior, 2003, p. 46).

Manjiviona (2003) stated that, "one of the misleading claims made by professionals working in this area is that children with Asperger Syndrome have a distinctive cognitive profile, usually incorporating a higher verbal I.Q.” (as cited in Prior, 2003, p. 56). A study by Griswold, Barnhill, Myles, Hagiwara, and Simpson (2002) on academic achievement revealed a group of young people with "an extraordinary range of scores, extending from significantly above average to far below what might be predicted for their assigned grade levels” (p. 98). Research shows that within that part of the autistic spectrum occupied Asperger Syndrome, there are wide differences. Yet, as Frith (2004) commented “Asperger Syndrome has a special cachet that hints at superior intelligence and perhaps even genius” (p. 673).

One of the diagnostic criteria for Asperger Syndrome is a narrow and obsessive range of interests such as inflexible adherence to rituals or a preoccupation with something that is abnormal in intensity or focus. There can be benefits to having a circumscribed interest. For example, Grandin’s autobiographical account (1995) outlines how her special ability has helped her design cattle pens that led to a career in animal husbandry. In the majority of cases, however, the child with Asperger Syndrome will struggle in trying to accommodate their circumscribed interest with daily living. Klin and Volkmar (2000) argue that, given the diverse ways in which Asperger Syndrome can present in children, interventions by professionals must be "highly individualised to address a child's specific needs while capitalising on the child's assets” (p. 340).

Asperger Syndrome is a fairly new diagnostic category, having only been included in diagnostic manuals since the 1990s. There have been few studies of how it is socially constructed. O’Dell and Brownlow (2005) carried out a discourse analysis on media reports linking the Mumps, Measles, and Rubella (MMR) vaccination with autism. This was an interesting piece of work but addressed itself purely to the MMR reports and not to the wider construction of autism or Asperger Syndrome. Brownlow and O’Dell (2006) studied an Internet chat room used by those with Asperger Syndrome, to see how they constructed themselves. This group constructed themselves positively and felt that they were the experts on their condition. They were often disparaging toward professionals, but felt that a diagnosis was ultimately helpful. The importance of looking at the socio-cultural production of Asperger Syndrome from a critical disabilities study viewpoint is highlighted. 
Nadesen (2005) views the development of Asperger Syndrome through a postmodern lens. She criticizes the use of the medical model to understand Asperger Syndrome, and focuses on the socio-cultural development of ASD. She argues that it must be contextualized historically within its time and states that "the public's fascination with autism, particularly its highfunctioning forms stems in large part from the idea that people with autism are technologically gifted and are particularly adept with computer technology” (Nadesen, 2005, p. 4). Asperger Syndrome paradoxically signifies pathology and special aptitudes, especially in the mathematical/technological arena. This speaks more about the contemporary power of technology, than about the lived reality of Asperger Syndrome.

Murray (2006) discussed how ASD is represented in films and novels. He contends that ASD are now strongly defined by films such as Rain Man (1988). These films construct ASD as including difficulty understanding social situations, obsessional preoccupations, and the "purportedly exceptional skills of the autist” (Murray, 2006, p. 31). Murray states that art misrepresents reality in important ways. He argues that the narrative space created by film reflects back upon the concerns of the "normal", while the reality remains hidden. Finally, he commented on the power of the media to create an image that is skewed to "spectacularize" ASD by constant reference to exceptional, almost superhuman abilities.

This paper will enter the debate on how people may obtain knowledge about Asperger Syndrome as a social and ideological entity. Foucault (1972) maintains that "to tackle the ideological function of a science in order to reveal and modify it” (p. 125), one should question it as a discursive formation. Discursive formations will have an effect on how practitioners relate to children. The staff who care for those children with Asperger Syndrome in out-of-home care can have the most profound impact on the lives of those children. Hawthorn (2005) describes the richness and intensity of relationship that a residential practitioner needs to develop with the child who has a disability. If practitioners are not prepared for the intensity of the task, they may fall back on a habitus (Bourdieu \& Wacquant, 1992) that is drawn from the messages that exist in wider discursive formations (such as seeing the disabled child as "victim", "tragic", or "impaired”). Practitioners who are not adequately prepared for their care task may believe that they do not have the ability or temperament to carry out this job, and may move away from the profession.

The term "discourse" is bound up with use of language. One of the most helpful theorists in this respect has been Fairclough, who said that discourse was "language as social practice determined by social structure” (Fairclough, 1989, p. 14). Language as social practice usually comes in the form of texts, such as newspaper articles. As language is determined by social structures, then an analysis of language can provide some indications as to the origin of ideas about social justice. Discourses are, in effect, ways of objectifying values and issues within society. The study of discourse owes much to postmodernism. Foucault (1980) stated that language of itself gives clues to social structures lying beyond the subjective self. The language and texts generated at particular points in history give clues about the structures of knowledge and power underlying them. He also said that power is something that permeates social institutions and determines whose voice is heard. The ideas of Foucault would suggest that aspects of social justice may be determined by texts concerning Asperger Syndrome, which are artefacts of the thinking which underlies much more than the writing. 


\section{Methodology}

This study is divided into two parts. One is an examination of texts dealing with Asperger Syndrome and the other is a field study of potential and newly recruited child care practitioners. The tool of enquiry used to interrogate the texts was Critical Discourse Analysis (Fairclough, 1989). Fairclough (1989) asserts that discourses determine action. As he said:

in seeing language as discourse and as social practice, one is committing oneself not just to analysing texts ... but to analysing the relationship between texts, processes and their social conditions (p. 21).

Fairclough was interested in how some ideas came to be highly visible and reported, while other ideas were absent. Reflecting Foucault, he felt that people apply to their everyday understandings of textual material an ideological lens that has been socially determined and of which they are largely unaware. Only by applying critical reasoning to the discourse can the researcher move beyond superficial meaning and explicate some of the discourses lying beneath the constructed text. Meaning-making is a negotiation between the writer, the reader, and wider ideas of social justice. This helps in gaining an understanding of how the discourse translates into practice and contributes to the habitus of child care practitioners.

The texts used in this study comprised extracts from autobiographical accounts of people with Asperger Syndrome, novels referring to people with Asperger Syndrome, and newspaper articles about Asperger Syndrome. The bulk of the texts submitted to analysis were newspaper articles. The reason for this is because these articles form a significant way for people to gain information and, potentially, to absorb ideological beliefs. For the majority of people in Western society, reading a newspaper makes up a significant part of their exposure to texts. It seemed reasonable to include a range of articles to which child care practitioners may have been exposed. Segments of two novels were included because novels, like newspaper articles, are artefacts of the thinking that produce them. Two autobiographies written by people with Asperger Syndrome were included as a way to ensure that the views of those most closely affected would be represented.

When examining the views of potential and newly recruited child care practitioners, focus groups and questionnaires were used. Two sets of focus groups were organized. The first groups represented potential staff and comprised students who were due to complete their studies at three further education colleges and who were about to seek employment. The second groups represented newly recruited practitioners working in two autism-specific residential settings. A total of five focus groups provided the data. Participants were also asked to complete a questionnaire, before the focus group took place. This served to standardize part of the process as the same questions were asked of all participants. The transcripts from the focus groups were submitted to content analysis, grouped into broad categories, and coded. 
International Journal of Child, Youth and Family Studies (2011) 3 \& 4: 473-493

\section{Findings of the Textual Analysis}

\section{Article One: “Mapping the autistic mind” (The Observer, 3 August 2003)}

The article begins with a short description of Jadyn, a child on the autism spectrum, and finishes with a statement about the rising incidence of autism. Two main themes emerge from the article. The first of these themes is the role of research and medical intervention in the lives of children affected by autism spectrum disorders. The second theme is an exploration of the nature of autism and Asperger Syndrome.

The first theme of the role of research and medical intervention clearly draws upon the discourses of disability and medicine. In terms of the discourse of medicine, the power of the medical research establishment is seen in the legitimation of the article. Using Van Leeuwen's categories of legitimation cited by Fairclough (2003), this article draws on authorization for its credibility (p. 98). This is drawn from the authority of the researchers who are quoted and discussed. The second theme explores the nature of autism and Asperger Syndrome. There are a range of phrases and words that valorize aspects of ASD. Some examples are: "very good at analysing systems"; "high-functioning, highly intelligent people”; "they will spend much time working on devices”. Most of the valorizations are around aspects of intelligence and technical ability. Hence, the existence of a discourse of autism and Asperger Syndrome begins to emerge. Embedded clauses also highlight this theme:

Luke Jackson, who has Asperger's Syndrome, which is a high-functioning form of the condition, is an articulate and intelligent boy who revealed his struggle to make sense of other people.

Alan Turing, the father of modern computing, was though to be mildly autistic.

These two embedded clauses refer such valorizations as an association with high functioning or an aptitude for computing.

A range of propositional assumptions is also apparent in the article. For example, in relation to people with Asperger Syndrome, they are said to be "highly intelligent people who have overcome some of their difficulties". This proposes that there are difficulties associated with Asperger Syndrome. A description in this text for the nature of these "difficulties", however, is vague. They include phrases such as: "impaired social development, specifically lack of eye contact"; or "struggle to make sense of other people”. The phrases use non-specific words, leaving the reader to construct Asperger Syndrome from equally vague information. Other vague words include "quirky" and "weird". These words imply that children with Asperger Syndrome represent a group with "difficulties” that are not, however, entirely clear.

The headline of the article refers only to autism, but the article is, in fact, about highfunctioning autism and Asperger Syndrome. The use of the word "autistic" in the headline serves to homogenize all children who are affected, instead of suggesting that there may be differences and nuances within autism. Finally, the article is accompanied by a large picture of Jadyn, sitting in front of a computer and turning to face the camera. The picture is a stylistic feature that 
International Journal of Child, Youth and Family Studies (2011) 3 \& 4: 473-493

reveals traces of the discourse of Asperger Syndrome, associating it with a degree of intellectual and perhaps technical proficiency.

\section{Article Two: “Andrew top of the class as he overcomes autism” (Evening Times, 26 November 2003)}

This article covers the annual awards given by the Scottish Qualifications Authority, the main awarding body for qualifications in Scotland. The main focus of the story concerns Andrew, a young person with Asperger Syndrome and reports that he achieved the best results for Higher Grades in the history of his school.

Two main themes emerge from the article. One is about Asperger Syndrome and educational achievement. The other is that of overcoming adversity. The article derives part of its legitimation from authorization by two directly quoted head teachers and an amorphous group of "teachers" who also have a direct quote attributed to them. In fact, three of the five direct quotes in the piece come from teachers. In addition, one of these quotes is repeated and highlighted in a feature box within the text. This signifies the privileged voice of education. The foreground purpose of the article is the reporting an awards event. In reality, however, it focuses on the achievements of one award winner. There is an existential assumption about where the achievement may lead in the following quote: "(Andrew) plans to go to Strathclyde University to study maths and computing science”.

Apart from one small two-word quote, Andrew's voice is mediated by the author. The only descriptions of the possible problems associated with Asperger Syndrome come from Robert McKay, a spokesperson from an autism charity, and from the author's narrative. McKay's contribution to an understanding of difficulties comes in the phrase, "living in a world where they don't understand social rules”, which is vague. The author states that: “Asperger's impairs communication skills, social understanding and imagination but not intellect”. This non-modalized declarative statement, with the contrastive clause at the end, indicates clearly how the author is committed to the article. Another valorization is the association that the author makes between Asperger Syndrome and the subjects of maths and computing. Andrew received five Higher Grades, yet only his ability in maths and computing is mentioned. In this text, part of the discourse of Asperger Syndrome includes (a) a special talent (b) that could be about maths or computing. A hyponymic relation develops between the term “Asperger Syndrome” and talents such as maths and computing.

Finally, the article is accompanied by a picture of Andrew, standing in front of a whiteboard. On the whiteboard behind him are geometric and algebraic equations. The image creates a stylistic association between Andrew and complex mathematics, suggesting that Asperger Syndrome is associated with mathematical ability.

\section{Article Three: “Michelangelo may have suffered Asperger's Syndrome” (The Scotsman, 1 June, 2004)}

This article outlines the findings of a research report on Asperger Syndrome. In the article, the researchers claim that Michelangelo had Asperger Syndrome. It proceeds to describe 
International Journal of Child, Youth and Family Studies (2011) 3 \& 4: 473-493

how Michelangelo's behaviour was indicative of Asperger Syndrome. The article further claims that Asperger Syndrome may have affected other exceptionally gifted historical figures. The film Rain Man is also mentioned.

There are two interlinked themes in the article. One is the theme of special talent. The other is the theme of the characteristics of Asperger Syndrome. This article sets up a significant relation of equivalence between the two themes in terms of its structure. This is marked by a higher-level contrastive semantic relation across the whole piece. The article alternates between descriptions of Michelangelo and descriptions of Asperger Syndrome. Co-locations serve to link special talent with Asperger Syndrome. For example: “Asperger’s sufferers, while socially disabled, possess phenomenal talents and huge powers of concentration-just like

Michelangelo”. This co-location is a relation of equivalence. The above example is also contains existential assumptions that people with Asperger Syndrome have special talents. This is not contested or modalized in any way by the use of pronouns such as "some" in front of the phrase "Asperger's sufferers" suggesting that special talent is a given feature of the condition. At the end of the article, the author refers to the film Rain Man. This film is an extremely powerful cultural marker for autism and Asperger Syndrome, as evidenced in the literature review. By referring to this film, the author invokes a visual image of the person with Asperger Syndrome. Even with this evocative image, however, the reader is not left to think about aspects of the film that showed Dustin Hoffman's character experiencing difficulties. The reader is, instead, immediately directed to the character's gift with numbers. A special ability with numbers as a feature of Asperger Syndrome appears once again.

\section{Article Four: "Schoolboy with autism to do battle on Mastermind” (The Scotsman, 4 May 2005)}

This article concerns Andrew, an 11-year-old boy with Asperger Syndrome who was scheduled to appear on the U.K. television quiz programme Junior Mastermind. Two themes emerge from the article. The main theme is a valorization of Asperger Syndrome. There is a less pervasive theme about the other contestants and the nature of this particular quiz programme. Contrastive clauses are used on several occasions to positively valorize certain characteristics of Asperger Syndrome: "Sufferers often find social situations confusing and are unable to make small talk or keep eye contact, but are outstanding at picking up details”. The contrastive clause here creates a value assumption through the creation of a dialectical relation. When looking at "characteristics" in the first part of the segment above, the author does not use any adjectives. When looking at the "ability to pick up facts", however, this characteristic is described as "outstanding", valorizing this characteristic above the others.

The headline includes the word "autism" but goes on to talk about someone with a diagnosis of Asperger Syndrome. This, once again, leads readers to the conclusion that the reported traits and special talents associated with Asperger Syndrome are applicable to all those children and young people affected by autism. The article outlines some of the difficulties associated with Asperger Syndrome. These include: "prone to anxiety attacks"; “difficult to deal with crowds and high noise levels". The final paragraph is interesting and reveals more traces of the discourse of Asperger Syndrome: 
International Journal of Child, Youth and Family Studies (2011) 3 \& 4: 473-493

A recent study for the Royal Society of Medicine diagnosed the artist Michelangelo as one of the most famous sufferers. Analysing accounts of the painter's life, experts claimed that he showed all the key traits of the syndrome.

This paragraph draws on the power of the discourse of medicine to legitimate the view that Asperger Syndrome is associated with special talent. The reader is left with a strong sense that special talents are shared by Michelangelo and Andrew and, by association, others with Asperger Syndrome.

\section{Article Five: "Keith Joseph, the father of Thatcherism, 'was autistic' claims Professor" (The Independent, 12 July 2006)}

This article covered an academic conference. One of the speakers, Professor Fitzgerald, presented his findings on a retrospective analysis of figures from recent and past history, including Keith Joseph, a Minister in the U.K. Thatcher government. Fitzgerald concluded that all of the historical figures he studied had Asperger Syndrome. The article has two main themes. One is a description of Keith Joseph. The other theme is about the relationship of Asperger Syndrome to special talent and exceptionality. Contrastive clauses are present:

Joseph - who died in 1994 - was a brilliant lawyer who served in Harold Macmillan’s government in the 1960s but was prone to eccentric behaviour and errors of judgement that can be attributed to his mental condition, said Professor Fitzgerald.

The first half of the sentence before the conjunction "but” serves to mark out Joseph's giftedness. After the conjunction, Joseph's behaviour is described. The contrastive nature of the sentence adds a conditional aspect to his "brillian(ce)" and sets up the existential assumption that his eccentricity and errors of judgement are part of Asperger Syndrome. The odd behaviour, however, did not stop him from being "brilliant”. There are interesting co-locations that identify Asperger Syndrome with special talent and exceptionality in a positive sense.

The article gets its legitimation from authorization. Professor Fitzgerald is consistently named at the beginning and end of sentences. The discourse of academia is drawn upon for authorization as references are made to the conference and to the Professor's academic title. A sentence in the second last paragraph sets up an existential assumption that Asperger Syndrome is a mild condition: "Like autism, of which it is a mild form, Asperger's runs in families". One of the final sentences highlights the relation with computing and intellect: "The professor of computer science with a brilliant mind, few friends and an obsessive interest in model trains is the classic sufferer”.

\section{Novel One: Atwood's Oryx and Crake (2003)}

The analysis concerns the beginning of the chapter entitled “Asperger's U”. The two main characters, Jimmy and Crake, are the key protagonists in this chapter. The chapter begins with the chapter heading "Asperger's U”. The chapter heading sets the tone for the rest of the chapter. Used in this way, the letter " $U$ " follows a common convention in North America, where universities are often referred to by this abbreviation. The co-location of "Asperger" with " $U$ ” in 
this context creates a value assumption about both the word "Asperger" and "university". Universities are highly valued in Western society as they supposedly attract the most intelligent people. This value is transferred by co-location to the word "Asperger".

The following series of quotes shows how Crake's character is developed and linked with Asperger Syndrome. The initial part of the segment contains Jimmy's reflections on what he felt were Crake's difficulties in having romantic relationships. The propositional assumption is that Crake finds it difficult to form relationships with the opposite sex and the value assumption is that this is not a positive aspect of his being: "Falling in love, although it resulted in altered body chemistry and was therefore real, was a hormonally induced delusional state, according to him [Crake]”. Crake's description of falling in love does not fall within the usual conventions of romantic fiction. There are no descriptions of the feelings and emotions normally associated with love. Instead, the process is described using terms from science and medicine. The sentence also states two almost-mathematical propositions: "Love $=$ altered body chemistry $=$ real/Altered body chemistry = delusional state = love”. The propositional assumption about this is that love, in Crake's eyes, is a mental illness. In terms of a value assumption, mental illness is viewed negatively in Western society and therefore falling in love is negative. The quote suggests that Crake is an overly rational scientific person who is out of step with the "normal" expectations about love in the West: "(sex) was on the whole a deeply imperfect solution to the problem of intergenerational genetic transfer”. The above quote gives Crake's views of sex as a process that exists for one outcome (procreation) and not as part of an emotional connection between two people. Once again, scientific language is used, that further incorporates this into Crake's personality.

The description of a game of chess between Crake and Jimmy is also interesting: "he already saw thirty moves ahead and was patiently waiting for Jimmy's tortoiselike mind to trundle up to the next rook sacrifice”. In Western society, chess is a game associated with intelligence. This link with intelligence is further strengthened by the reference to "Jimmy's tortoiselike mind". The propositional assumption set up here is that Crake's mind is much quicker than that of Jimmy. The use of the verb "trundle" and the noun "sacrifice" serves to emphasize Jimmy's lack of ability and the inevitability of his defeat by Crake. In the following segment, the author/narrator describes Watson Crick Institute that Crake attends as a student:

Watson Crick was known to the students there as Asperger's U, because of the high percentage of brilliant weirdos that strolled and hopped and lurched through its corridors. Demi-autistic, genetically speaking; single-track tunnel vision minds, a marked degree of social ineptitude - these were not your sharp dressers_- and luckily for everyone there, a high tolerance for mildly deviant public behaviour.

The additive and elaborative clauses (emphasis added) following “Asperger's U” serve to give the author/narrator's view of aspects of Asperger Syndrome. The word "brilliant" sets up the propositional assumption that this group is highly intelligent. The phrase "demi-autistic" is particularly unusual. One feature of Atwood's writing is that she invents new words. This invented phrase uses the prefix "demi" that calls to mind the word "demi-god", a partly divine being. Behaviour that may be deviant is modalized by the use of the adverb "mildly." In an email exchange with Jimmy, Crake compares Watson Crick to their old high school, HelthWyzer: 
International Journal of Child, Youth and Family Studies (2011) 3 \& 4: 473-493

Compared to this place, HelthWyzer was a pleebland, Crake replied.

It was wall-to-wall NTs.

NTs?

Neurotypicals.

Meaning?

Minus the genius gene.

In the above segment, the italics are used to highlight the e-mail messages. The term "neurotypical" is a term commonly used in non-fiction literature and on websites within the Asperger online community. It refers to people who are not on the autism spectrum. Crake also defines "neurotypicals" as being "minus the genius gene”. The propositional assumption here is that all those who attend "Asperger's U” have the genius gene.

This analysis reveals traces of the discourse of Asperger Syndrome. Atwood is talking from her position in the real world, where messages about Asperger Syndrome circulate. Although it is never stated that Crake has Asperger Syndrome, the reader infers this. Aspects of the discourse of Asperger Syndrome that have been textured into this chapter are intelligence (or even genius), clumsiness, social discomfort, some odd behaviour, and high degree of ability in science. The voice of the less-able person with Asperger Syndrome is entirely absent once again.

\section{Novel Two: Haddon's The Curious Incident of the Dog in the Night-Time (2003)}

The analysis concerns Chapter 83 of the book. The first point to note is that the book only contains 51 chapters. Christopher, however, orders the book chapters according to prime numbers because he likes prime numbers. Chronologically, this chapter is actually the 23rd in the book. This unusual convention created by the main character immediately has traces of the discourse of Asperger Syndrome that suggests a mathematical gift.

The majority of this chapter is written in the first person so in this way the presence of the young person with Asperger Syndrome is immediate. The style of this piece of fictional writing is very immediate. In this chapter, Christopher talks about being an astronaut:

To be a good astronaut you have to be intelligent and I am intelligent. You have to understand how machines work and I'm good at understanding how machines work. You also have to be someone who would like being on their own in a tiny spacecraft.

References to intelligence and a technical proficiency are present in this segment. In the chapter, Christopher talks about how he would cope with being on a spaceship: “And I wouldn't be homesick at all because I'd be surrounded by lots of things I like, which are machines and computers and outer space”. Traces of the discourse of Asperger Syndrome such as being 
International Journal of Child, Youth and Family Studies (2011) 3 \& 4: 473-493

associated with computers are present. The use of the conjunction "and" at the beginning of the sentence occurs many times throughout the chapter and, indeed, throughout the novel. Although not strictly grammatical, this linguistic device suggests a continuous generating and processing of facts, through the use of additive clauses and sentences. The device works to produce a sense that Christopher's mind works like a computer, continually producing and processing information. While this is, in all probability, the author's intention, the use of this device provides another trace of how computers are part of the discourse of Asperger Syndrome.

Some chapters are more explicit about Christopher's mathematical and technical ability. Other chapters are concerned with the problems that Christopher faces and his reactions to these. In the book, the character of Christopher is intelligent, mathematically gifted, and with a great ability to remember facts. He also has great difficulty with social relationships, and is extremely anxious in strange situations.

\section{Autobiography One: Jackson’s Freaks, Geeks and Asperger Syndrome (2002)}

This text talks about Luke's thoughts on the use of the term “Asperger Syndrome”. The text invites comments or thoughts from other young people with Asperger Syndrome as in the following quote:

Hands up those of you reading this who have been called a freak or a geek or a boffin or a nerd? (Or any variation on this theme!) I am pretty sure that would be the majority of AS kids, probably adults too.

This use of the interrogative mood occurs several times to signal the invitation to the reader to become involved more fully in the text. While inviting others into the conversation, however, the use of the terms "freak", "geek", "boffin", and "nerd" all serve to paint a particular picture of Asperger Syndrome. The contemporary use of the terms "geek" and "nerd" is often associated with a single-minded interest, particularly in computers. A "boffin" is a term used for a scientific or technical expert. These expressions contain traces of the discourse of Asperger Syndrome associating it with proficiency in science or computers. The word "freak" is more pejorative than the other three expressions. An alternative meaning for "freak", however, is someone who has an obsessive interest in something. For example, the phrase "health freak" is a common one in Western society to describe someone who is obsessed with becoming healthy. Both uses of the word "freak", in this case, reflect the texturing together of the discourses of disability and Asperger Syndrome.

Luke Jackson's book is interesting because it gives a view of Asperger Syndrome from a young person's perspective. Luke is honest about his difficulties but is also extremely positive about his diagnosis. He admits that he was not very good at maths, for example. It is also very clear, however, that Luke is an articulate young person. These self-reports contribute to traces of the discourse of Asperger Syndrome that suggests that those affected are particularly able, if a little "freaky" to use Luke's word. The voices of those less able than Luke, however, are absent. 
International Journal of Child, Youth and Family Studies (2011) 3 \& 4: 473-493

\section{Autobiography Two: Willey's Pretending to be normal: Living with Asperger's Syndrome (1999)}

Book introductions are important, acting as signposts to its content. Many readers go to the introduction of a book, its chapter headings, and summary to decide whether or not the book is relevant or interesting (Cottrell, 2003). The introduction to this book begins with the following sentences: "The autism umbrella is vast. Within its boundaries is a wide range of abilities and disabilities; a wide range of differences". This foregrounds the author's recognition of difference. The use of the word "abilities" before the word "disabilities" immediately suggests her valorization of ASD. However, its co-location with "disabilities" also introduces a degree of ambivalence. This sense of ambivalence runs throughout her book and reflects her life as an able and intelligent woman who has also experienced some harrowing events. The author consistently alludes to the fact that Asperger Syndrome can affect people in many different ways. When her description of Asperger Syndrome is given, however, a clearer idea of her orientation to difference emerges:

At their best they will be the eccentrics who wow us with their unusual habits and streamof-conscious creativity, the inventors who give us wonderfully unique gadgets ... the geniuses who discover new mathematical equations, the great musicians and writers and artists who enliven our lives. At their most neutral, they will be the loners who never know quite how to greet us, the aloof who aren’t sure they want to greet us, ... a few of the professors everyone has in college. At their most noticeable, they will be the lost souls who invade our personal space ... the people who sound like robots, the characters who insist they wear the same socks and eat the same breakfast day in and day out.

A trace of the discourse of Asperger Syndrome that involves its association with giftedness informs the first part of the paragraph giving a background valorization to certain traits over the more "neutral" and "noticeable" traits referred to later. A value assumption is created with the use of nominalizations. For example, instead of using "people who behave eccentrically", or "people with eccentric behaviour", the author chooses the nominalized version. This serves to reify this characteristic. Finally, the words "eccentric", "genius", and "mathematical” crop up again, creating a hyponymic relation between those terms and Asperger Syndrome.

The author is clearly an intelligent articulate person, working as a researcher in the field of psycholinguistics and learning style differences. Although the book does give clear insights into how she has experienced Asperger Syndrome and some of its associated difficulties, the association of her title, “Doctor”, with “Asperger Syndrome” serves to contribute to the discourse of Asperger Syndrome as being associated with academic achievement and high intelligence.

\section{Findings of the field study}

The questionnaires and transcripts were analyzed to explore the beliefs and experiences of potential and newly recruited child care practitioners. A number of themes emerged and these are discussed. 


\section{Sources of knowledge}

In the questionnaire, students were asked where they had gained most of their knowledge about ASD. Practitioners were asked from where they had learned about ASD before they started in their post. Only six of the students learned at college. Both groups referred to films, TV, books, and newspaper articles as being a source of knowledge. Practitioners also quoted the Internet as a source of knowledge, while none of the students quoted this as a source. This may be because if someone is actually recruited to work with ASD, they may carry out some research before they go for an interview. In the focus groups, there were examples of students and practitioners talking about the film Rain Man when describing sources of knowledge. A total of seven references were made to the film across the three student focus groups. This appears to demonstrate the power of this particular film as a cultural marker for ASD. There were also direct references made to television, newspaper or magazine reports about people affected by ASD. This indicates that some of the students have been exposed to the media messages that exist in the wider discourse.

\section{Understanding of Asperger Syndrome and Autism}

Few students connected autism and Asperger Syndrome with behavioural problems or challenging behaviour. The construction of autism by the student group contained more negative labels and a less positive evaluation of autism than of Asperger Syndrome. None of the practitioners reported "giftedness" as a feature of autism while three of the students did. Five of the students reported "giftedness" as a feature of Asperger Syndrome. While five of the practitioners also reported "giftedness" as a feature of Asperger Syndrome, it should be noted that four of these five practitioners had not yet worked directly with a child or young person affected by Asperger Syndrome. This may suggest that students and less experienced practitioners have absorbed a message from the media that giftedness is associated with this. The questionnaire also sought data on the construction of Asperger Syndrome from students. The results are shown in Table 1 :

Table 1: Concepts used in the students' construction of AS

\begin{tabular}{|l|l|}
\hline Concepts used & Numbers \\
\hline Disability & 8 \\
\hline Challenging behaviour / & 6 \\
\hline behavioural problem & \\
\hline Social interaction & 4 \\
\hline Flexibility/imagination & 6 \\
\hline Giftedness & 3 \\
\hline
\end{tabular}


Only 17 of the 28 students mentioned Asperger Syndrome. The remaining 11 students reported that they did not know what Asperger Syndrome was or that they had not heard of it. (The figures in the table add up to more than 17 because some students used several sentences when describing Asperger Syndrome). Five of the respondents mentioned autism and they were clear that Asperger Syndrome was a "milder" form of autism or a "higher functioning" form, possibly associated with a degree of giftedness. Some of their responses were as follows:

“Asperger's syndrome to me is like autism but a milder condition.”

"I think Asperger's is a higher functioning form of autism."

"It is a kind of autism, where they are hyper-intelligent."

"I think it's a kind of autism. The person is very clever or has special abilities."

"Quite intelligent person. The person may become quite hyper. A form of autism."

\section{Understanding the challenges}

Children affected by ASD who are in out-of-home care tend to be there because their behaviour cannot be sustained in a mainstream school or home environment. As such, the children who live in autism-specific facilities will present challenges to practitioners. Students and practitioners were asked for their perceptions about these challenges. When asked about the specific difficulties they may face, students believed that there would be problems in communication, flexibility/imagination, and challenging behaviour and that these would be more prevalent in autism than in Asperger Syndrome. Practitioners were asked what problems they faced in their day-to-day work with their young clients. For autism, the responses differed from the students in that the frequency of problems they experienced in the areas of communication and interaction was higher, in practice, than what had been imagined by the student group. For Asperger Syndrome, the responses differed from the students in that the frequency of problems they experienced in practice was higher in the areas of communication, flexibility/imagination, and challenging behaviour than had been imagined by the student group. Students had overestimated the amount of challenging behaviour they may experience from clients with autism but had underestimated the amount of challenging behaviour in Asperger Syndrome. In addition, students had not mentioned cognitive impairment or self-injury, while practitioners reported that they encountered these in their work. This is illustrated in Table 2:

Table 2: Comparison of perception v. reality of problems

\begin{tabular}{|l|l|l|l|l|}
\hline Problem & $\begin{array}{l}\text { Autism } \\
\text { (students) }\end{array}$ & Autism & AS & AS \\
& (practitioners) & (students) & (practitioners) \\
\hline Communication & $35 \%$ & $78 \%$ & $23 \%$ & $31 \%$ \\
\hline Flexibility/Imagination & $35 \%$ & $28 \%$ & $12 \%$ & $23 \%$ \\
\hline Social Interaction & $18 \%$ & $33 \%$ & $47 \%$ & $46 \%$ \\
\hline
\end{tabular}


International Journal of Child, Youth and Family Studies (2011) 3 \& 4: 473-493

\begin{tabular}{|l|l|l|l|l|}
\hline Challenging behaviour & $71 \%$ & $61 \%$ & $23 \%$ & $54 \%$ \\
\hline Cognitive impairment & 0 & $17 \%$ & 0 & $8 \%$ \\
\hline Self-injury & 0 & $17 \%$ & 0 & 0 \\
\hline Mental health issues & 0 & 0 & $12 \%$ & 0 \\
\hline Intelligence & $14 \%$ & 0 & $6 \%$ & 0 \\
\hline
\end{tabular}

The results indicate that students may underestimate some of the difficulties they will face when they go into practice. This was particularly marked in relation to communication (rf., autism) and challenging behaviour (rf., Asperger Syndrome). Practitioners were asked to identify the behaviours that they found most difficult to deal with. They were also asked if they had expected to deal with that particular behaviour before they came to work with children affected by ASD. Table 3 outlines the answers to this question:

Table 3: Most difficult behaviours expected

\begin{tabular}{|l|l|l|l|}
\hline Type of behaviour & Expected & $\begin{array}{l}\text { Expected } \\
\text { (conditional) }\end{array}$ & Not expected \\
\hline Self-injury & 1 & 5 & 3 \\
\hline Aggression & 2 & 2 & 0 \\
\hline Limited interaction & 1 & 0 & 0 \\
\hline Task avoidance & 0 & 0 & 1 \\
\hline Spitting & 0 & 1 & 0 \\
\hline Snatching food & 0 & 0 & 0 \\
\hline Children scaring other children & 1 & 0 & 1 \\
\hline
\end{tabular}

The respondents identified seven behaviours that they found most difficult to deal with. Self injury was quite significant. Five members of staff said they expected to deal with it but the reality was different from their expectations. These were some responses:

"One of the main behaviours I find difficult to deal with is self-injury. Although I expected this sort of behaviour it's hard to accept when you see it.” 
International Journal of Child, Youth and Family Studies (2011) 3 \& 4: 473-493

"Self-injuring. It's hard to understand, harrowing to see and difficult to deal with. I will deal with this behaviour here but don’t know if I'm ready for it.”

Three respondents said that they did not expect to be working with self-injury at all. Four respondents identified aggression as the most difficult behaviour to work with. Although all of the respondents said they expected to work with it, two of them found the reality different from their expectations:

“Aggression. I was aware that this could happen but not the regularity.”

"Aggression but not constantly."

Only five out of the 18 respondents felt able to give an unconditional response that they had expected to deal with the behaviour they had identified.

\section{Stress factors in residential practice and difference between belief and reality}

In focus group transcripts, only four statements indicating stressors were evident in the student transcripts. The transcripts from the newly appointed practitioners revealed that there were 26 statements that related to stressors. The stressors could be grouped into three subthemes. The first sub-theme was experiencing difficulties with specific issues relating to the children. Thirteen of the statements related to specific issues that included self-injury (4), aggression (4), communication (3), and flexibility/imagination (2). The second sub-theme was how the lack of experience and perceived lack of preparation was adversely affecting them as practitioners. Seven of the statements related to this sub-theme. The third sub-theme was the effect that organizational issues could have on practitioners. The practitioners were asked what the main differences were between their expectations of their work and their actual experience of the task. The answers clustered around four sub-themes. The first of these was that expectations were not matched by reality, especially when it came to how severely affected the children and young people could be by their ASD. The second sub-theme identified was that of challenging behaviour, particularly aggression. The third sub-theme that was mentioned was that respondents had different perceptions of what their job roles would be. The fourth sub-theme was the individual differences of the children and young people.

\section{Discussion}

Critical disabilities studies and social justice discourse invite researchers to look beyond the obvious and to highlight the power/knowledge in society. In this study, textual analysis revealed that while the discourse of Asperger Syndrome is sited within a wider disability discourse, there is a degree of ambivalence because it contains ideas that it is correlated to high intelligence, special talents (especially in maths or computing), and possibly with genius. There is also a prevailing belief within the discourse that Asperger Syndrome is a "mild disorder". Yet the literature review revealed that children with Asperger Syndrome can have severe problems and that the idea that children with Asperger Syndrome have high intelligence is contested. The notion of genius has attached itself to Asperger Syndrome. If the Asperger genius exists, however, why is this account privileged over all others in the discourse? Where is the voice of the ordinary Asperger Syndrome child? 
The conceptualization of Asperger Syndrome within the discourse is problematic because it is not fully inclusive of all of its constituency. There are a number of people affected by Asperger Syndrome who are of high intelligence and who have made a great success of their lives. In addition, there are groups of people affected by Asperger Syndrome who have constructed their identities in a positive way with little reference to prevailing beliefs, especially about disability. Once again, such self-constructed identities that challenge the able-bodied hegemony should be celebrated. The prevailing discourse of Asperger Syndrome in Western society is inclusive of these individuals and can assist them to meet and fulfil their personal aims. In terms of Fairclough's schema, however, the social problem consists of those children who are completely invisible within the discourse. When a social group is absent from the discourse, it is difficult then to begin to address their particular rights from a viewpoint of social policy or provision.

Like Nadesen (2005), I would contend that Asperger Syndrome is articulated discursively not only through the clustering of symptoms but also through the structure and beliefs relating to middle-class discourses that articulate childhood as the locus of class mobility and intellectual superiority as the pathway to success. The hegemony that defines disability also incorporates concepts of normality, able-bodiedness, and, most importantly in this instance, able-mindedness. It is within such a set of discourses and practices that this obstacle arises. Disability is viewed negatively in our society, and learning disabilities are the most negatively viewed among all forms of disability because such disabilities affect the intellect. From this it may be deduced that a "disability" that is associated with high intelligence might be construed as a "lesser evil". Here lies the ambiguity of Asperger Syndrome. The discourse of Asperger Syndrome sites it within a wider "dis-ability" discourse but also within the "ability" discourse. When examining Asperger Syndrome, the emergence of an identity that is often characterized in the media as "genius" may seem to place those in Western society with that diagnosis at an advantage. Any foregrounding of the more serious issues that can be experienced by children with Asperger Syndrome would challenge the hegemonic valorization of the intellect.

Practitioners who work in out-of-home care with children affected by Asperger Syndrome are among the least powerful of the professional groups involved in this area. They tend to have a shorter period of formal training for their work tasks than other groups of professionals. In terms of the development of their habitus as professional caregivers, therefore, they may be more susceptible to messages in the wider discourse. The textual analysis gave examples of the types of printed media to which they may be exposed. The fieldwork for this study alluded to some interesting relationships between the messages in the discourse and the myths versus the reality of working with children who are severely affected by Asperger Syndrome. Among potential staff and newly recruited practitioners, it was noted that films, TV, books, and the printed media were important sources of knowledge.

Some key differences emerged between the potential staff and newly recruited practitioners. In particular, Asperger Syndrome had giftedness as part of its construction for both potential staff and for those current practitioners who had not yet worked with a child with Asperger Syndrome. This reflects the power of the discourse of Asperger Syndrome. Potential staff were also more inclined to believe that the task of caring for such children may have relatively little stress associated with it. It is in this area that the messages contained within the 
International Journal of Child, Youth and Family Studies (2011) 3 \& 4: 473-493

discourses of Asperger Syndrome can have a negative impact upon newly recruited staff. The group of newly recruited staff reported a much wider and specific series of stressors than did the potential staff group. This could indicate that the habitus is maladapted for the task of caring for this group of children.

Newly recruited practitioners reported that their expectations were not matched by the reality of the work. These expectations had been partly formed by the discourse and had come to form part of their habitus in relation to their identity as residential practitioners. They also experienced the level of challenging behaviour as stressful. Once again, the expectations generated by the discourse of Asperger Syndrome did not allude to this. Finally, the construction of autism and Asperger Syndrome did not clearly demonstrate the individual differences between children on the autistic spectrum. It was almost as if the staff expected that their young clients would all conform to a stereotypical image. Perhaps this image may have reflected the images contained in the discourse - that of the quirky, eccentric child with a possible talent or high IQ. I would suggest that as a result of the discourse of Asperger Syndrome and the wider discourse of autism, some staff may be lost to the profession. High staff turnover in out-of-home care can have a negative impact upon children. If they have a constant change of staff, this can affect the consistency of care and cause some distress for them. Therefore, it is important that the prevailing discourses of autism and Asperger Syndrome are challenged in a productive way.

\section{Conclusion}

There is no fixed way of being a child and there is no fixed way of being autistic. Moss and Petrie (2002) took an ecological view and suggested that we should be creating spaces for children to be and to exist at that time, without a notion of driving them out to a "better" place. Understandings like this should be disseminated into wider society. In keeping with the social model of disability, there needs to be a social valuing of children as human beings and not just as potential productive cogs in an economic machine. We must write about and represent these children as real people living ordinary lives and not simply accept the extraordinary representations that exist. The constructs of Asperger Syndrome and autism come ready-made with a set of rules and procedures implicit within the construct. By questioning the construction of the child with Asperger Syndrome as a discursive formation, this study has attempted to disentangle the complex web of related practices in order to appreciate the interplay between myth and reality.

Asperger Syndrome is not a purely existential entity, with an independent essence outside of human relationships. It is reified and mediated within sets of social practices. It can be viewed, in fact, as an ideological entity whose meaning is created in the social milieu. The way that phenomena such as Asperger Syndrome are described in texts is conditioned by the discourses within which it is embedded. Discursive practices arise from types of social relations. Mediated social relations such as reading books or newspapers, and sharing this information are one way of ensuring that people integrate the predominant messages, and thereby acquire the template for predominant power/knowledge relations within society. This then links to the practice of care as these messages come to form part of the habitus. 
International Journal of Child, Youth and Family Studies (2011) 3 \& 4: 473-493

\section{References}

Atwood, M. (2003). Oryx and Crake. London: Bloomsbury.

Bourdieu, P., \& Wacquant, L. (1992). An invitation to reflexive sociology. Cambridge: Polity Press.

Brownlow, C., \& O’Dell, L. (2006). Constructing an autistic identity: AS voices online. Mental Retardation, 44(5), 315-321.

Cottrell, S. (2003). The study skills handbook (2nd ed.) Basingstoke: Palgrave Macmillan.

Fairclough, N. (1989). Language and power. London: Longman.

Fairclough. N. (2003). Analysing discourse: Textual analysis for social research. London: Routledge.

Fitzgerald, M. (2003). Autism and creativity: Is there a link between autism in men and exceptional ability? London: Routledge.

Fitzgerald, M. (2005). The genesis of artistic creativity: Asperger's Syndrome and the arts. London: Jessica Kingsley.

Foucault, M. (1972). The archaeology of knowledge. New York: Pantheon.

Foucault, M. (1980). Power/knowledge: Selected interviews and other writings, 1972-77 (C. Gordon, Ed.). Brighton: Harvester.

Frith, U. (1991). Autism and Asperger's Syndrome. Cambridge: Cambridge University Press.

Frith, U. (2004). Confusions and controversies about Asperger Syndrome: The Emmanuel Miller lecture. Journal of Child Psychology and Psychiatry, 45(4), 672-686.

Gillberg, C. (1991). Clinical and neurobiological aspects of Asperger Syndrome in six family studies. In U. Frith (Ed.), Autism and Asperger's Syndrome (pp. 122-146). Cambridge: Cambridge University Press.

Grandin, T. (1995). Thinking in pictures. New York: Doubleday.

Griswold, D. E., Barnhill, G. P., Myles, B. S., Hagiwara, T., \& Simpson, R. L. (2002). Asperger Syndrome and achievement. Focus on Autism and other Developmental Disabilities, 2, 94-102.

Haddon, M. (2003). The curious incident of the dog in the night-time. London: Doubleday. 
International Journal of Child, Youth and Family Studies (2011) 3 \& 4: 473-493

Hawthorn, M. (2005). Giving a voice to disabled young people in residential care. In D. Crimmens and I. Milligan (Eds.), Facing forward: Residential child care in the 21st century (pp. 57-70). Lyme Regis: Russell House.

Jackson, L. (2002). Freaks, geeks and Asperger Syndrome. London: Jessica Kingsley.

Klin, A., \& Volkmar, F. R. (2000). Treatment and intervention guidelines for individuals with Asperger Syndrome. In A. Klin, F. R.Volkmar, \& S. S.Sparrow (Eds.), Asperger Syndrome (pp. 340-366). New York: The Guilford Press.

Manjiviona, J. (2003). Assessment of specific learning difficulties. In M. Prior (Ed.), Learning and behaviour problems in Asperger Syndrome (pp. 55-84). New York: The Guilford Press.

Moss, P., \& Petrie, P. (2002). From children's services to children's spaces: Public policy, children and childhood. London: Routledge.

Murray, S. (2006). Autism and the contemporary sentimental: Fiction and the narrative fascination of the present. Literature and Medicine, 25(1), 24-45.

Nadesen, M. H. (2005). Constructing autism: Unravelling the "truth" and understanding the social. London: Routledge.

O’Dell, L., \& Brownlow, C. (2005). Media reports of links between MMR and autism: A discourse analysis. British Journal of Learning Disabilities, 33, 194-199.

Reitzal, J., \& Szatmari, P. (2003). Cognitive and academic problems. In M. Prior (Ed.), Learning and behaviour problems in Asperger Syndrome (pp. 35-54). New York: The Guilford Press.

Willey, L. H. (1999). Pretending to be normal: Living with Asperger Syndrome. London: Jessica Kingsley.

Wing, L. (1981). Asperger's Syndrome: A clinical account. Psychological Medicine, 11, 115129.

Wing, L. (1988). The continuum of autistic characteristics. In E. Schopler \& G. B. Mesibov (Eds.), Diagnosis and assessment in autism (pp. 91-110). New York: Plenum Press.

Wing, L. (1991). Asperger's syndrome and Kanner's autism. In U. Frith (Ed.), Autism and Asperger Syndrome (pp. 93-121). Cambridge: Cambridge University Press. 